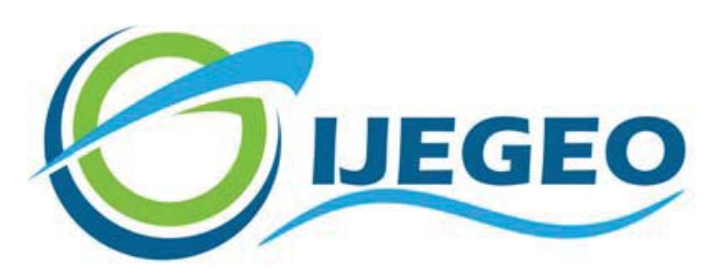

International Journal of Environment and Geoinformatics (IJEGEO) is an international, multidisciplinary, peer reviewed, open access journal.

\title{
Regulation of Mineral Resource Activities in Antarctica
}

\section{Nasıh Sarp ERGÜVEN, Burcu ÖZSOY, Sinan YİRMİBEŞOĞLU, Özgün OKTAR}

\author{
Chief in Editor \\ Prof. Dr. Cem Gazioğlu \\ Co-Editors Prof. Dr. Dursun Zafer Şeker, Prof. Dr. Şinasi Kaya, \\ Prof. Dr. Ayşegül Tanık and Assist. Prof. Dr. Volkan Demir
}

Editorial Committee (June 2022)

Assoc. Prof. Dr. Abdullah Aksu (TR), Assoc. Prof. Dr. Uğur Algancı (TR), Assoc. Prof. Dr. Aslı Aslan (US), Prof. Dr. Levent Bat (TR), Prof. Dr. Paul Bates (UK), İrşad Bayırhan (TR), Prof. Dr. Bülent

Bayram (TR), Prof. Dr. Luis M. Botana (ES), Prof. Dr. Nuray Çağlar (TR), Prof. Dr. Sukanta Dash (IN), Dr. Soofia T. Elias (UK), Prof. Dr. A. Evren Erginal (TR), Assoc. Prof. Dr. Cüneyt Erenoğlu (TR), Dr. Dieter Fritsch (DE), Prof. Dr. Ç; Prof. Dr. Manik Kalubarme (IN), Dr. Hakan Kaya (TR), Assist. Prof. Dr. Serkan Kükrer (TR), Assoc. Prof. Dr. Maged Marghany (MY); Prof. Dr. Micheal Meadows (ZA), Prof. Dr. Nebiye Musaoğlu (TR), Prof. Dr. Masafumi Nakagawa (JP), Prof. Dr. Hasan Özdemir (TR), Prof. Dr. Chyssy Potsiou (GR), Prof. Dr. Erol Sarı (TR), Prof. Dr. Maria Paradiso (IT), Prof. Dr. Petros Patias (GR), Prof. Dr. Elif Sertel (TR), Prof. Dr. Nüket Sivri (TR), Prof. Dr. Füsun

Balık Şanlı (TR), Dr. Duygu Ülker (TR), Prof. Dr. Seyfettin Tsaş (TR), Assoc. Prof. Dr. Ömer Suat Taşkın (TR), Assist. Prof. Dr. Tuba Ünsal (TR), Assist. Prof. Dr. Sibel Zeki (TR) 


\title{
Regulation of Mineral Resource Activities in Antarctica
}

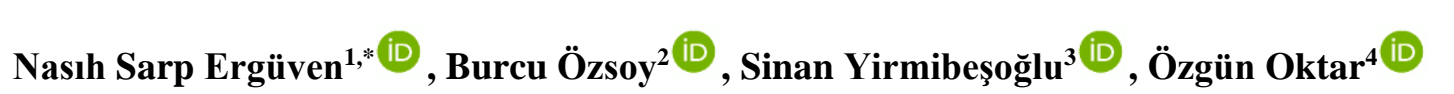

${ }^{1}$ Ankara University, Faculty of Law, Department of International Law, Ankara, Turkey

${ }^{2}$ TUBITAK Marmara Research Center (MRC) Polar Research Institute (PRI), İstanbul Technical University, Maritime Faculty, Department of Maritime Transportation and Management Engineering, İstanbul, Turkey

${ }^{3}$ TUBITAK MRC PRI, Kocaeli, Turkey

${ }^{4}$ TUBITAK MRC PRI, Istanbul Technical University, İstanbul, Turkey

* Corresponding author: N. S.Ergüven

Received 01.04.2021

* E-mail: erguven@law.ankara.edu.tr Accepted: 29.10 .202

How to cite: Ergüven et al., (2022). Regulation of Mineral Resource Activities in Antarctica, International Journal of Environment and Geoinformatics (IJEGEO), 9(2): 081-086. doi. 10.30897/ijegeo.907991

\begin{abstract}
Mineral resource activities in Antarctica were brought to the agenda at the $6^{\text {th }}$ Antarctic Treaty Consultative Meeting (ATCM) held in Tokyo for the first time in 1970. The Convention on the Regulation of Antarctic Mineral Resource Activities (CRAMRA), which regulates the issue in detail, could not enter into force after France and Australia decided not to sign the Convention. The Protocol on Environmental Protection to the Antarctic Treaty (PEPAT) was signed after the Special ATCMs that took place in Madrid in 1991 to review the Antarctic Treaty. The Protocol entered into force on 14 January 1998, after the ratification of all Consultative Parties. PEPAT, which does not modify the Antarctic Treaty in any way, is among the legal documents within the Antarctic Treaty System (ATS) as its annex. Unlike CRAMRA, with the provision of PEPAT Article 7, mineral resource activities are completely prohibited. The only exception to the related prohibition is mineral resource activities for scientific research. This does not mean that the mentioned activities will be carried out in an unlimited way. These activities are subject to PEPAT and Annex 1 Environmental Impact Assessment. Continuity of the absolute prohibition of mineral resource activities is a significant issue. Accordingly, in accordance with Article 25/1 of PEPAT, provisions of the PEPAT may be modified or amended by the unanimous agreement of the Consultative Parties including Article 7. Apart from this, in the ongoing paragraph of the same article, after the expiration of 50 years from the date of entry into force of PEPAT, this period corresponds to 2048, a conference will be held to review the functioning of PEPAT with the notification of any of the Consultative Parties. It was envisaged that the proposed amendments to the PEPAT at the Review Conference would be adopted by a majority of the Parties, including 3/4 of the States which are Consultative Parties at the time of PEPAT's entry into force (1998), including Article 7, which prohibits mineral resource activities. When signed, PEPAT, which is considered to be difficult to enter into force since all of the Consultative Parties approval has to be given, took effect in line with the emergence of the common interest in this direction. This shows the Consultative Parties' commitment to the protection of Antarctica and especially the prohibition of mineral resource activities. The determination in question was once again expressed by the Declaration accepted after the $32^{\text {nd }}$ ATCM and the Resolution adopted in the $39^{\text {th }}$ ATCM, although they were not legally binding. Especially in the Resolution, the emphasis on both the continuity of the prohibition on mineral resource activities and the incorrect belief in the media that PEPAT will be expired in 2048 is noteworthy.
\end{abstract}

Keywords: Antarctica, the Protocol on Environmental Protection to the Antarctic Treaty, Antarctic Treaty System, Mineral Resources

\section{Introduction}

Polar Regions, especially the Antarctic Continent, bring about multidisciplinary scientific research even through social sciences. Many researchers share their data and opinions on climate change, environmental issues, territorial claims, precious metals, international law, etc. Particularly Antarctica contains many conspicuous features which will be on agenda every time (Çetin and Büyüksağnak, 2021).

The international public has started to pay more attention to environmental issues in the first half of the $20^{\text {th }}$ century. In this process, within the scope of international law, developments regarding the responsibility of states have been experienced, international environmental law has developed and emerged as a separate branch of law. At a time when international environmental law began to take shape on the responsibility that will arise after the damage to the environment occurs, an approach based on the precautionary principle aimed at preventing damage has come to the fore within the Antarctic Treaty System (ATS). Thus, ATS started to set an important example in terms of international environmental law and contributed to the development of international law. (Rothwell, 1996).

The other essential aspect of this status is the legal regime of the Antarctic Continent. From the viewpoint of environmental governance, state sovereignty is the key element. In the territories under state sovereignty, it is the obligation of the state to apply rules with respect to environmental protection. Since there are no territorial sovereigns in Antarctica, an international collective approach led by international institutions, in this case, the Antarctic Treaty Consultative Meeting (ATCM), is 
responsible to govern the environment of the Antarctic (Koivurova, 2013).

Considering the Antarctic Treaty alone, it does not appear to have a direct impact on the above-mentioned process. Within the scope of Article 9 of the Treaty, which regulates the procedure of measures to be taken in the Consultative Meetings, there is the expression "preservation and conservation of living resources in Antarctica", apart from this, there is no provision regarding the protection of the Antarctic environment in the Treaty. This situation has been tried to be overcome through the legal documents that constitute ATS. The first of the mentioned documents is the Agreed Measures for the Conservation of Antarctic Fauna and Flora dated 1964. With the measures, Antarctica has been declared a special conservation area as the first separate status given to a continent in international law. Measures, which constituted the most comprehensive document for the protection of natural life on the date of its acceptance, could not fully fulfill the final purpose of the protection of Antarctica, since they are not legally binding. In the ongoing process, ATS developed with the Convention for the Conservation of Antarctic Seals of 1972 and the Convention on the Conservation of Antarctic Marine Living Resources of 1980 to protect animals whose life depends on Antarctic continent and its habitat (Chaturvedi 1996; Nanda, 2012; URL 1; URL 12; URL 13; URL 14).

The fact that the Article 9 of the Antarctic Treaty only mentions living resources, this process, which is valid for the protection of living resources, has not come to the agenda for a long time in terms of mineral resource activities. The main reason for the aforementioned situation is that the main factor that was emphasized during the signing of the Antarctic Treaty was the claims of sovereignty over the continent and primarily trying to prevent the possibility of these causing an international conflict. In the negotiation process, mineral resource activities were not included in the agenda in order not to create a new conflict area in addition to the existing issues. At the same time, the fact that the technological possibilities of the period did not allow mineral resource activities in Antarctica completely prevented the states from taking initiatives in this direction (Rothwell, 1996; Wolfrum, 125).

\section{Materials}

Mineral resource activities in terms of Antarctica first came to the agenda at the $6^{\text {th }}$ ATCM held in Tokyo in 1970. The adoption of Recommendations on the subject, was possible in the $7^{\text {th }}$ and $8^{\text {th }}$ ATCMs gathered between 1972 and 1975. In both Recommendations, it was underlined that technological developments increase the interest in possible mineral exploration and exploitation activities in Antarctica, but detailed negotiations and evaluations are needed, especially in terms of determining the environmental impacts of the aforementioned activities on Antarctica. Even at this stage, the references of the Consultative Parties to the environmental impacts of mineral resource activities are noteworthy (URL 2; URL 3).
In the special session held within the scope of the $9^{\text {th }}$ ATCM in London in 1977, the report of the expert group on the preliminary assessment of the environmental impact of mineral exploration/exploitation activities in Antarctica, which was formed within the Scientific Committee on Antarctic Research (SCAR), was discussed. In the Recommendation adopted as a result of the negotiations, it was stated that the protection of Antarctica is the main element and that the Consultative Parties should not violate the interests of humanity in the aforementioned issue. More importantly, it was agreed that the Consultative Parties should not engage in any exploration/exploitation activities until a common regime regarding mineral resource activities in Antarctica is established (Ronald 1983; URL 4).

In the $10^{\text {th }}$ ATCM gathered in Washington in 1979 , on the grounds that unregulated mineral resource activities will damage the sensitive ecosystem of Antarctica, the basic elements of the common regime, which were specified in the previous meeting, were emphasized. Accordingly, within the scope of the regime, determining the possible effects of mineral resource activities on Antarctica and evaluating the relevant actions in terms of acceptability should be included. At the same time, the rules for the protection of Antarctica should form the basis of the regime in question. These and the elements determined in the above ATCMs for mineral resource activities in Antarctica were determined as the agenda of the Special ATCM, which was decided to meet on the subject at the $11^{\text {th }}$ ATCM that came together in 1981 in Buenos Aires (URL 5).

The first session of the Special ATCM on the mineral resources of Antarctica was held in Wellington in 1982, and after eleven rounds of negotiations, the 1988 Convention on the Regulation of Antarctic Mineral Resource Activities (CRAMRA) was signed. Within the scope of Article 1 of the CRAMRA, mineral resources are defined as, all non-living natural non-renewable resources, including fossil fuels, metallic and nonmetallic minerals (URL 6). Based on the issues determined by the above-mentioned Recommendations, the Convention has become an innovative document in terms of international environmental law. First of all, a new structure consisting of the Antarctic Mineral Resources Commission, the Antarctic Mineral Resources Regulatory Committee, and the Scientific, Technical and Environmental Advisory Committee has been envisaged, and regular meetings on the subject titled Special Meeting of Parties have been added to these. Within the scope of the said institutional structuring, the state parties are obliged to obtain an exploration permit before starting any mineral exploration activity. In order to obtain this permit, it is stipulated that the possible effect of the activity proposed and an assessment of its impact on Antarctica should be determined in detail by the relevant state. In this context, the detailed notification submitted by the State Party must also contain a description of the capacity to respond effectively to accidents, especially those with potential environmental effects. Considering the relevant process, it is seen that the initiation of mineral exploration activities by the state parties within the scope of 
CRAMRA depends on detailed conditions (Rothwell, 1996).

In the period following the signing of CRAMRA, the adverse environmental disasters that increase the perception of the international public opinion about the environment caused a demand to not allow mineral resource activities in Antarctica. Following this, the possibility of CRAMRA to come into force has been eliminated with the announcement of France and Australia, which are Consultative Parties whose approvals are mandatory for the CRAMRA to come into force, that they will not sign the Convention (Rothwell, 1996).

Although it regulates the mineral resource activities in Antarctica under detailed and strict conditions, it is not possible to indicate that CRAMRA is a legal document that completely prohibits them. It is very important to evaluate today's developments that the will of the Consultative Parties for the realization of these activities does not show an unlimited nature and the demand for an absolute prohibition in terms of mineral resource activities is brought to the agenda even before CRAMRA goes into effect.

By the signing of the PEPAT after the Special ATCMs conducted in Madrid in 1991 in line with Article 12/2-a of the Antarctic Treaty, the approach to the absolute prohibition of mineral resource activities in Antarctica, which prevents the CRAMRA from entering into force was reflected in practice. PEPAT was entered into force on 14 January 1998, after the ratification of all Consultative Parties. PEPAT, which does not modify the Antarctic Treaty in any way, is among the legal documents within the ATS as one of its annexes. PEPAT, which emerged as an alternative to CRAMRA, also incorporated the Agreed Measures for the Conservation of Antarctic Fauna and Flora dated 1964, which is devoid of binding, with the Annex 2 Conservation of Antarctic Fauna and Flora, and made it a binding text. Besides, together with Annex 1 Environmental Impact Assessment, Annex 3 Waste Disposal and Waste Management, Annex 4 Prevention of Marine Pollution, Annex 5 Area Protection and Management, and Annex 6 Liability Arising from Environmental Emergencies, PEPAT is the most comprehensive and effective of the legal documents within the scope of ATS. In addition to the existing principles applied in Antarctica in terms of international environmental law, new regulations and concepts have been brought to the agenda by PEPAT. Annexes other than Annex 6 are in effect with PEPAT. Turkey completed the ratification process of the PEPAT and all of its Annexes on 24.05.2017 (UNTC, 1991).

The geographical coverage of PEPAT, which is a supplement of the Antarctic Treaty, is in the area south of $60^{\circ}$ South Latitude, including all ice shelves, designated as the Antarctic Treaty Zone. This is the result of the comprehensive approach that has the main aim to protect the Antarctic ecosystem on land and at sea as a whole. In addition to this, the objective of the PEPAT which is regulated in Article 2 including dependent and associated ecosystems of Antarctica causes interpretations asserting that the protection of the Antarctic environment can be achieved also by some activities in the north of $60^{\circ}$ South Latitude (Stephens, 318).

With PEPAT, Antarctica has been declared as a natural reserve, devoted to peace and science. This situation has no precedent for any other continent in international law. Antarctica has been previously declared as a special conservation area with the Agreed Measures for the Conservation of Antarctic Fauna and Flora dated 1964. However, this document is not legally binding and the aforementioned statement is included in the Preamble of the Measures. The natural reserve status envisaged for Antarctica under PEPAT is a binding provision regulated in Article 2. Thus, an important obligation is imposed on the State Parties to protect the Antarctic environment. The concept of the special conservation area that was mentioned in the Agreed Measures for the Conservation of Antarctic Fauna and Flora dated 1964 was also referred to in the Preamble of PEPAT (URL 1; URL 7; URL 13).

In the preparatory process of PEPAT, the approach to the purification of the continent from all activities in line with concepts such as "world park" was not accepted, and the continuation of activities such as scientific research and tourism was ensured within the scope of the concept of natural reserve and the protective provisions regulated by the Protocol (Joyner, 1992). The boundary regarding the current situation has been drawn in terms of mineral resource activities.

Unlike CRAMRA, mineral resource activities are completely prohibited with Article 7 of PEPAT. The only exception to this is scientific research related to mineral resource activities. This does not mean that mineral resource activities can be carried out in line with scientific research without any limitation. These activities are subject to the regulations of PEPAT and Annex 1 Environmental Impact Assessment and it is possible to be carried out only for scientific purposes in line with the fulfillment of the requirements here (UNTC, 1991).

\section{Results}

The issue of the validity of the prohibition on mineral resource activities is important and needs to be examined in more detail. Accordingly, PEPAT provisions, including Article 7, which prohibits mineral resource activities, may be amended by the Consultative Parties unanimously in accordance with Article 25/1 of PEPAT. Apart from this, in the ongoing paragraph of the same article, after the expiration of the 50-year period following the date of entry into force of PEPAT, this period corresponds to the year 2048, with the notification of any of the Consultative Parties, a conference will be held to review the functioning of PEPAT. The proposed modification or amendment in the provisions of PEPAT in the Review Conference, including Article 7, shall be adopted by the majority of the parties covering 3/4 of the states with Consultative Party status at the time of the adoption of PEPAT. In order for the modifications adopted in this way to enter into force, the approval of 3/4 of the states that are currently Consultative Parties, including the approval of 
all states with Consultative Party status on the time of the adoption of PEPAT is necessary (URL 12; UNTC, 1991).

The prohibition on mineral resource activities constitutes a special case in terms of both the modifications that can always be made unanimously by the Consultative Parties and the possible modifications in the Review Conference, which can be held in 2048. According to Article 25/5-a of PEPAT, the said prohibition continues unless there is a binding legal regime that includes an agreed method for determining whether such activities are acceptable and, if so, under what conditions. Any proposed amendment or modification to the ban in the Review Conference shall also include such a binding legal regime on the subject. In other words, for the amendment or modification proposals for the ban on mineral resource activities in Antarctica to be accepted, they must contain binding provisions regarding the regulation of the activity in question, as in CRAMRA. (UNTC, 1991

After PEPAT came into effect, some significant developments in the same direction took place on the subject. The first of these is the Declaration adopted at the $32^{\text {nd }}$ ATCM in Baltimore in 2009 on the occasion of the $50^{\text {th }}$ anniversary of the signing of the Antarctic Treaty. In Paragraph 5 of the Declaration, the Consultative Parties reaffirmed their commitment to Article 7 of PEPAT prohibiting all kinds of activities related to mineral resources except scientific research (URL 7).

In the following period, a Resolution at the $39^{\text {th }}$ ATCM gathered in Santiago in 2016 has been adopted on the subject that many in the public and especially the media stated that PEPAT expires in 2048. In the Resolution, the ongoing commitment regarding the related ban has been underlined; it has been declared that the ban will continue to be implemented as a matter of highest priority in line with the aim of protecting the Antarctic environment and dependent and associated ecosystems (URL 8). The same approach was repeated with the Declaration adopted at the $42^{\text {nd }}$ ATCM held in Prague in 2019, as in the Declaration adopted in 2009 on the occasion of the $50^{\text {th }}$ anniversary of the signing of the Antarctic Treaty (URL 9).

\section{Discussion and Conclusion}

Mineral resource activities which are not regulated by the Antarctic Treaty have become a crucial part of the agenda of Antarctica since 1970. At the point reached today, these activities have been prohibited with Article 7 of PEPAT. Mineral resource activities, which are possible with the fulfillment of the detailed conditions with CRAMRA, have been eliminated before being reflected in the implementation with the signing of the PEPAT.

As well as the processes and regulations described above, determining the perspective of mineral resource activities in Antarctica in terms of international law, is also important. In international law, the fact that treaties formed by the State Parties are brought to the agenda requires a balance of power in this direction. This is because, under international law, a legislative authority does not exist, as in other branches of law. The emergence of norms in terms of international law requires the sovereign states that are in an equal position with each other to agree in this direction, and this necessitates the existence of a balance of power on the subject, as stated above. When the balance of power in terms of Antarctica was combined with the common interest not to create a new conflict area during the Cold War, it was possible to sign the Antarctic Treaty.

A similar situation was experienced during the entry into force process of the PEPAT. When it was signed, PEPAT, which was considered difficult to enter into force due to the approval of all the Consultative Parties, came into force in line with the common interest that emerged in this direction. This demonstrates the commitment of the State Parties to the protection of Antarctica and, in particular, to banning mineral resource activities. This determination, although not legally binding, was once again expressed in the Declaration adopted after the $32^{\text {nd }}$ ATCM and the Resolution adopted in the $39^{\text {th }}$ ATCM. Especially in the Resolution, the emphasis on the commitment of the ban on mineral resource activities and the misinterpretations in the media that PEPAT expires in 2048 is important.

At this point, after the expiration of the 50-year period following the date of entry into force of PEPAT, that is, in 2048, it is necessary to correctly evaluate the conference that was decided to convene to review the functioning of PEPAT with the notification of any of the Consultative Parties. The regulation in question is a provision that is frequently encountered in order to facilitate States to ratify the treaty in terms of treaties such as the Antarctic Treaty, where the common interest and the balance of power are difficult to occur simultaneously. With regards to treaties in which the balances are correctly formed, the review conferences in question either never convene (Montreux Convention) or when they meet, as in the Antarctic Treaty, new legal documents like PEPAT that strengthen the treaty emerge.

In addition to all these, the comments stating that PEPAT will expire in 2048 and that mineral resource activities will be possible, despite the existence of Article 25/1 of PEPAT, which makes it possible to amend the provisions of PEPAT unanimously by the Consultative Parties, do not reflect the exact situation.

On the other hand, another element that needs to be focused on related to the topic is the newly emerging actors in Antarctic relations. By this approach, the future of the prohibition on mineral resource activities can be examined in an inclusive manner. In this context, the most current and active actor is the Republic of Turkey.

Since 2017, the Antarctic studies, which are held under the auspices of the Presidency of the Republic of Turkey; are carried out under the responsibility of the Ministry of Industry and Technology and coordinated by the Polar Research Center of Istanbul Technical University (PolReC) within the scope of the National Polar Science Program (2018-2022) which is prepared by the contributions of 120 Turkish Scientists from 36 
institutions (URL 10). In order to ensure that polar research activities are carried out with more international participation and embraced in a systematic manner, the Polar Research Institute (PRI) under the Scientific and Technological Research Council of Turkey (TUBITAK) was established on 21 November 2019. The main aim of the Institution is to conduct the National Polar Science Program (2018-2022) in collaboration with the related institutions to reach the final goals, which are becoming a consultative member of the Antarctic Treaty System and an observer state to the Arctic Council (Organizational Culture and Policies, 2021; Çetin, 2021). Intensive scientific activities carried out in this direction are sometimes overshadowed by such inaccurate and incomplete evaluations.

Turkey also completed the harmonization process of the PEPAT with its domestic law. The regulation about the Implementation of Protocol on Environmental Protection to the Antarctic Treaty by the Ministry of Environment and Urban Planning has entered into force on 13.06.2020 by being published in the Official Gazette numbered 31154 (URL 11). In addition to this, the Republic of Turkey continues its activities to strengthen and maintain the regime of Antarctica, which is used only for peaceful purposes and where scientific investigation and cooperation are essential. This process can be observed through the documents brought before the agenda of ATCM and the Committee for Environmental Protection (CEP) by the Republic of Turkey. A total number of 66 documents consists of Background, Information and Working Papers related to diverse agenda items have been submitted by the Republic of Turkey since 2016 (Secretariat of the Antarctic Treaty, 2016).

Since the beginning of the involvement of the Republic of Turkey in Antarctic relations and diplomacy, through the abovementioned process, the commitment of Turkey to the protection of the Antarctic environment and the prohibition on mineral resource activities is clear. The main outcome from the analysis of the mentioned process is the commitment to the prohibition on mineral resource activities is not only valid for the Consultative Parties. The Non-Consultative Parties like the Republic of Turkey that start recently to involve in Antarctic diplomacy, are also committed to the prohibition on mineral resource activities.

In this regard, the impact of non-governmental organizations related to the environmental governance of the Antarctic also needs to be addressed. Since the Antarctic has been designated as a continent for peace and science by the Antarctic Treaty, scientific nongovernmental organizations have taken part from the beginning of the process. In this context, SCAR even held a formal status in the negotiation period of the Convention for the Conservation of Antarctic Seals of 1972. SCAR has also contributed to the governance of mineral resource activities with the abovementioned report of the expert group on the preliminary assessment of the environmental impact of mineral exploration/exploitation activities in Antarctica in 1977. In the ongoing process, besides scientific organizations, environmental non- governmental organizations like the Antarctic and Southern Ocean Coalition (ASOC) and Greenpeace International also have started to contribute to the field. Especially the positive effect of Greenpeace having Australia and France pull out of CRAMRA and to the adoption of PEPAT is noteworthy (Koivurova, 2013).

Inaccurate and incomplete evaluations stating that PEPAT will expire in 2048 and that mineral resource activities will be possible in Antarctica especially in the media sometimes overshadow the intensive scientific activities carried out on the Continent. Besides this kind of approach to the topic related, by taking into account all of the explanations above, it can be stated that all of the subjects of the Antarctic diplomacy including the Consultative Parties, Non-Consultative Parties and nongovernmental organizations are fully committed to the protection of the Antarctic environment and the prohibition on mineral resource activities.

\section{Acknowledgements}

This article is an expanded and updated version of the issues briefly mentioned in the presentation by the authors within the scope of the $4^{\text {th }}$ National Polar Science Workshop on the $22^{\text {nd }}$ of October, 2020 organized by TUBITAK, MRC, PRI.

\section{References}

Çetin, O. (2021). Relationship with Marine Environmental Consciousness and Maritime Culture in Turkey, International Journal of Environment and Geoinformatics, 8(3), 245-255, doi.10.30897/ ijegeo.862055

Çetin, O., Büyüksağnak, Y. B. (2021). Turkey's Interest in the Arctic Region: the Possible Effects of being a Party to the Svalbard Treaty. International Journal of Environment and Geoinformatics, 8(3), 350-358, doi. 10.30897/ijegeo.887540.

Chaturvedi, S. (1996). The Polar Regions: A Political Geography.

Joyner, C.C. (1992). The 1991 Madrid Environmental Protocol: Rethinking the World Park Status of Antarctica. Review of European Community and International Environmental Law, 1(3), 328-339.

Koivurova, T. (2013). Multipolar and Multilevel Governance in the Arctic and the Antarctic. American Society of International Law Proceedings, 107, 443446, doi:10.5305/procannmeetasil.107.0443

Nanda, V. (2012). International Environmental Law and Policy for the 21st Century

Organizational Culture and Policies (2021). PRI. Retrieved 1 March 2021 from https://kare.mam.tubi tak.gov.tr/en/aboutpri/organizational-culture-andpoli cies.

Ronald F. Frank (1983) Convention on the Conservation of Antarctic Marine Living Resources, Ocean Development and International Law, 13:3, 291-345, doi.10.1080/00908328309545733

Rothwell, D.R. (1996). The Polar Regions and the Development of International Law. Cambridge: Cambridge University Press 
Secretariat of the Antarctic Treaty, Meeting Documents Archive.

Stephens, T. (2011). The Arctic and Antarctic Regimes and the Limits of Polar Comparativism. German Yearbook of International Law, 54, 315-350.

UNTC (1991). Protocol on Environmental Protection to the Antarctic Treaty.

URL 1. ATS (1964). Agreed Measures for the Conservation of Antarctic Fauna and Flora.

URL 2. ATS (1972). Recommendation VII-6, Study and Discussion of the Exploitation of Antarctic mineral resources.

URL 3. ATS (1975). Recommendation VIII-14, Antarctic Mineral Resources and Environmental Impact.

URL 4. ATS (1977). Recommendation IX-1, Future Regime on Antarctic Mineral Resources.

URL 5. ATS (1979). Recommendation X-1, Preparation for an Antarctic Mineral Resources Regime.

URL 6. ATS (1988). Convention on the Regulation of Antarctic Mineral Resource Activities.

URL 7. ATS (2009). Washington Ministerial Declaration on the Fiftieth Anniversary of the Antarctic Treaty.

URL 8. ATS (2016). Resolution 6 (2016), Confirming Ongoing Commitment to the Prohibition on Antarctic Mineral Resource Activities, Other than for Scientific Research; Support for the Antarctic Mining Ban.

URL 9. ATS (2019). Prague Declaration on the Occasion of the Sixtieth Anniversary of the Antarctic Treaty.

URL 10. National Polar Science Programme (2018-2022).

URL 11. Regulation on the Implementation of Protocol on Environmental Protection to the Antarctic Treaty.

URL 12. UNTC (1961). The Antarctic Treaty. Signed at Washington, on 1 December 1959.

URL 13. UNTC (1972). Convention for the Conservation of Antarctic Seals.

URL 14. UNTC (1983). Convention on the Conservation of Antarctic Marine Living Resources.

Wolfrum, R. (1986). Antarctic Mineral Resources Regime. Acta Juridica, 1986, 125-132. 